CHRISTOPHER A. SIMS

University of Minnesota

\title{
Output and Labor Input in Manufacturing
}

THE RELATION between output and labor input in manufacturing is important in quantitative analysis of economic fluctuations. Empirical work on this topic generally supports the conclusion that labor inputs respond with a delay, and not in full proportion, to changes in output. Thus, variations in output are accompanied by corresponding variations in average labor productivity. This phenomenon is something of a paradox, for shortrun increasing returns to labor, or SRIRL, are difficult to rationalize if the sector being explained is assumed to operate on a static production function in which labor is the most variable factor. One need not make this assumption, and a variety of plausible deviations from it, which can explain the qualitative empirical results, have been advanced. It also seems possible that some of the apparent SRIRL reported in previous studies reflects statistical bias in estimating the labor-output relation.

Note: Research results described in this paper were obtained with financial support of the National Science Foundation grant GS 36838. Some support was supplied also by the Cowles Foundation. 
Most previous regression studies of this relation have used quarterly data, ${ }^{1}$ and the estimates have often suggested that most of the response of labor input comes in the same quarter in which output changes. When an estimated lag distribution has such a form, the discrete estimates may not be a reliable guide to the underlying dynamics. ${ }^{2}$

Also, most previous studies have estimated single-equation distributed lag regressions, treating labor input as the dependent variable. The justification for doing so appears to be that output changes are thought to be causally prior to employment changes in the firm-level behavioral mechanisms most often invoked to explain SRIRL. Since these mechanisms do not generate a theory of the error term in the aggregate labor-output relation, they do not justify making labor the dependent variable in a regression. ${ }^{3}$ Indeed, if some of the error in the relation resides in output, inappropriate regressions of labor on output might imply spuriously large estimates of SRIRL.

The statistical procedures of this paper sharpen estimates of the laboroutput relation by using monthly data, by estimating regressions with both output and labor as the dependent variable (testing the hypothesis that right-hand variables are exogenous), and by using only weak maintained hypotheses about the forms of estimated lag distributions.

This paper shrinks the paradox of SRIRL in two ways. First, the empirical results show that the response of manhours of production workers in manufacturing industries to a change in output is essentially complete within six months (which was implicit in the results of earlier studies), and that the total response is fully proportionate (which was not). It should be noted that the empirical work in this paper is confined to production workers and in no way examines the existence of SRIRL for other workers, whose employment is presumably less variable.

Second, the theoretical discussion shows that, once the formation of expectations is treated realistically, a standard dynamic theory of decisionmaking under uncertainty does not imply that the sum of coefficients in

1. An important exception is Ray C. Fair, The Short-Run Demand for Workers and Hours (Amsterdam: North-Holland, 1969). Fair uses monthly data, as does this study, but works at a finer level of disaggregation.

2. For discussion of the effects of temporal aggregation on distributed lag relations, see Christopher A. Sims, "Discrete Approximations to Continuous Time Distributed Lags in Econometrics," Econometrica, Vol. 39 (May 1971), pp. 545-63.

3. Correspondingly, the fact that in the theory of consumer behavior price is causally prior to quantity in the consumer's decision does not imply that regressions of market quantity on price can be interpreted as demand curves. 
estimated lag distributions of labor on output represents the static optimum response of labor to output. Thus even where the total response of labor to output is less than fully proportionate, a nonconcave static production function is not implied.

\section{The SRIRL Paradox}

It is mildly paradoxical that fluctuations in output should tend to induce less than proportionate fluctuations in labor inputs. Presumably, most other inputs are less flexible than labor and therefore vary less as output changes. If a production function relating output to inputs shows constant returns to scale, percentage changes in output are a weighted average, with positive weights summing to one, of percentage changes in inputs. But the point of the empirical SRIRL phenomenon is precisely that output fluctuates proportionately more than does labor, which is only one of the inputs to production. Since there is no strong empirical evidence of aggregate increasing returns to scale in the United States, and increasing returns are difficult to reconcile with the standard competitive model of microeconomics, SRIRL is a paradox.

If inventories exist, output measured by deflated sales obviously can vary more than actual production over short periods. Even if labor input responded immediately and more than proportionately to production changes, it might then respond with a lag to "output" changes, in a pure timing effect. If production of finished goods were measured directly, similar pure timing effects might arise if there were inventories of goods-in-process or postponable maintenance tasks in the production process. But lags due to pure timing effects cannot explain the lack of proportionality in the eventual total response of labor input to properly measured output.

The more widely accepted explanations of SRIRL rest on the cost of adjusting labor input. In one version, part of the work force is regarded as fixed over the relevant time horizon, either by contract or by the need to man the fixed capital stock regardless of output. Alternatively, the work force is treated as homogeneous, but changing it rapidly is assumed to incur costs. ${ }^{4}$

4. Two pieces of work based on theory of this type are Thomas A. Wilson and Otto Eckstein, "Short-Run Productivity Behavior in U.S. Manufacturing," Review of Economics and Statistics, Vol. 46 (February 1964), pp. 41-54; and M. Ishaq Nadiri and Sherwin Rosen, $A$ Disequilibrium Model of Demand for Factors of Production (Columbia University Press for the National Bureau of Economic Research, 1974). 
Clearly there are plausible explanations of labor-output relations that would explain SRIRL over varying time horizons. Careful statistical estimation is needed to evaluate their quantitative importance and the implied behavioral structure. The following sections present a discussion of statistical issues and of the relation between estimation and structure as these apply to the analysis of the labor-output relation. Quantitative results are presented and discussed in subsequent sections.

\section{Structural Interpretation of the Regressions}

Suppose that in every month, $t$, each firm in the industry has an ideal level of labor, $L^{*}(t)$. This ideal level depends only on variables the firm cannot control, such as market input and output prices, and possibly shifts in the firm's own short-run demand curve. Were it not for the costs associated with adjusting actual labor, $L(t)$, they would always equal $L^{*}(t)$. To illustrate how such costs could give rise to a distributed lag relation of $L$ to $L^{*}$, assume that, in any period, $t$, the tradeoff between the costs of deviating from $L^{*}$ and the costs of rapidly changing $L$ is determined by the cost function ${ }^{5}$

$$
C(t)=a\left[L(t)-L^{*}(t)\right]^{2}+b[L(t)-L(t-1)]^{2} .
$$

If the firm chooses $L(t)$ at time $t$ to minimize expected discounted costs,

$$
E_{t}\left[\sum_{s=0}^{\infty} C(t+s) R^{s}\right]
$$

where $R$ is the discount factor, it can be shown that the firm's behavior will be described by

$$
L(t)-A L(t-1)=(1-A)(1-B) \sum_{s=0}^{\infty} B^{s} E_{t} L^{*}(t+s),
$$

where $E_{t}$ denotes the expectation based on information available up to

5. It would be more natural to formulate the dynamic optimization problem in continuous time. A short appendix in which this is done and in which the implications of rational expectations and the existence of inventories is explored is available from the author on request. It would also be natural to have $L$ and $L^{*}$ as vectors of factor inputs, and $a$ and $b$ as matrices. This procedure would lead to a set of distributed lag relations, one for each factor input, but the qualitative conclusions of the analysis would remain the same. 
time $t$ and $A$ and $B$ are parameters that depend on $a, b$, and $R .^{6}$ In the theoretical models used to justify previous econometric work on the relation of labor and output, it has been assumed that expectations are staticthat $E_{t}\left[L^{*}(t+s)\right]=L^{*}(t)$ for all $s$ and all $t$. This implies that the right-hand side of $(1)$ is simply $(1-A) L^{*}(t)$, so that the distributed lag relation between $L$ and $L^{*}$ is given by

$$
L(t)-A L(t-1)=(1-A) L^{*}(t) .
$$

This is a Koyck lag distribution whose coefficients sum to one. When some exogenous influence changes $L^{*}$, the lag distribution implies that eventually $L$ will adjust in full proportion to the change.

But now suppose that in fact $L^{*}(t)$ contains a trend component, $\bar{L}^{*}(t)$, that, over the relevant time horizon, can be predicted without error; and another component, $L^{*}(t)-\bar{L}^{*}(t)$, that has expected value zero but is serially correlated. A forecast that puts $L^{*}$ permanently at its current level then makes no sense. Instead, it will be natural to forecast a more or less rapid convergence of $L^{*}$ to its trend line $\bar{L}^{*}$-for example,

$$
E_{t}\left[L^{*}(t+s)\right]=\bar{L}^{*}(t+s)+G^{s}\left[L^{*}(t)-\bar{L}^{*}(t)\right],
$$

where $G$ is a constant between 0 and 1 that governs how quickly $L^{*}$ approaches its trend. ${ }^{7}$ If in addition $\bar{L}^{*}$ is an exponential function of time, (1) implies the following equation instead of (2):

$$
L(t)-A L(t-1)=(1-A)(1-B)(1-B G)^{-1} L^{*}(t)+T(t),
$$

where $T$ is an exponential function of time. Now the lag distribution implies less than fully proportionate total response of $L$ to $L^{*}$. This is intuitively reasonable, since now no level of $L^{*}$ is expected to persist indefinitely. ${ }^{8}$

6. This relation follows from the principle of first-period certainty equivalence. See H. Theil, Economic Forecasts and Policy (Amsterdam: North-Holland, 1958), pp. 507-14; and Herbert A. Simon, "Dynamic Programming under Uncertainty with a Quadratic Criterion Function," Econometrica, Vol. 24 (January 1956), pp. 74-81. Application of this principle to a dynamic theory of the firm is not new; see, for example, Charles C. Holt and others, Planning Production, Inventories, and Work Force (Prentice-Hall, 1960).

7. Such a forecast would actually minimize the variance of forecast error, $e$, if $L^{*}(t)-\bar{L}^{*}(t)=G\left[L^{*}(t-1)-\bar{L}^{*}(t-1)\right]+e(t)$, where $e$ is serially independent, and the information available at time $t$ was equivalent to that contained in current and past values of $L^{*}$.

8. This result arises in essentially the same way in which an economy characterized by rational expectations may display a distributed lag relation of unemployment to the rate of change of prices in which the sum of coefficients is nonzero, as explained by Robert E. Lucas, Jr., "Econometric Testing of the Natural Rate Hypothesis," in Otto Eckstein 
To generate an industry-level relation requires summing across firms. In this process, many exogenous influences on $L^{*}$ that are important at the firm level will become trivial. Furthermore, some variables that might not plausibly be assumed exogenous at the firm level may naturally be regarded so when measured as industry aggregates. This seems a particularly important point for output, but applies also to input and output prices if firms have some short-run flexibility in the relation of these prices to market averages.

In this paper, industry output is the sole explicitly measured exogenous influence on $L^{*}$. In principle, others, particularly input and output prices, should be included. If the estimated regressions are to be interpreted as reflecting forecasting and adjustment processes like those that lead to (3), one hopes that the omitted exogenous influences are well measured by the exponential trend that enters all the estimated relations, and that forecasts of industry output are no better than those obtainable from its own history. If this pair of assumptions is not at least approximately correct, the estimated regressions are likely to fail exogeneity tests.

Besides the negative conclusion that the sum of coefficients on current and lagged $L^{*}$ need not be one, models like that discussed here yield positive conclusions that may help in interpreting results. The parameters $A$ and $B$ tend to zero as $b / a$ tends to zero-that is, as the costs of adjustment diminish relative to the costs of deviating from $L^{*}$. Thus if $E_{t}\left[L^{*}(t+s)\right]$ is close to $L^{*}(t)$ for a short period into the future, as seems reasonable, equation (2) will become nearly accurate, with $A$ near zero, as adjustment costs go to zero: when adjustment costs are small, adjustment will be rapid and nearly fully proportionate. Similarly, the smaller is $G$ the closer to one will be the sum of coefficients on lagged $L^{*}$ in (3); in industries where deviations of output from trend are short-lived, the degree of SRIRL, as measured by the total response of labor to output, should be large. Note that in two industries with the same cost function, and thus the same $A$ and $B$, the total response of $L$ to $L^{*}$ could still differ because of differences in $G$, or more generally in the serial correlation properties of the output series: interindustry differences in the size of total response of $L$ to $L^{*}$ need not imply differences in the speed of the response.

(ed.), The Econometrics of Price Determination (Board of Governors of the Federal Reserve System, 1972), p. 57. The behavioral insight embodied in the result is similar to the distinction between "permanent" and "transitory" income in Milton Friedman, $A$ Theory of the Consumption Function (Princeton University Press, 1957). 


\section{Temporal Aggregation}

In this study, temporal aggregation cannot be dealt with in a footnote devoted to the peculiarities of the data. The empirical results and the analysis presented below suggest that it could be the source of a substantial portion of the observed residuals in output-labor relations. Furthermore, the method of temporal aggregation for U.S. data on labor input and output is a likely source of certain systematic biases.

Data on employment and average weekly hours of production workers, on which the "labor" variables of this study and many others are based, apply to the payroll period that includes the 12th of the month, and are thus monthly samplings of weekly averages. ${ }^{9}$ Data on production and sales in manufacturing, on the other hand, are monthly samplings of monthly averages. Relative to output data, then, labor data are less smoothed, and are shifted back in time by about one-tenth of a month.

The estimated lag distribution in a regression of output on labor will have its mean reduced by 0.1 month by the time shift in the data and will include a bias toward local smoothness generated by the tendency of the lag distribution to correct for the greater smoothness of the output series. On the assumption that labor data are exactly and always 0.25 -month averages centered 40 percent of the way through the month while the output data are full-month averages, methods similar to those I have used elsewhere allow an exact characterization of these biases. ${ }^{10}$ Thus suppose that the true relation between output and labor in continuous time is the identity $Y=L$. Then, assuming $Y$ and $L$ in fact change only slowly, ${ }^{11}$ the first row of the table below gives the lag distribution for $L$ on $Y$ estimated in a large sample of the discrete data, and the next two rows show, respectively, the separate effects of the time shift and of the greater smoothness of observed $Y$. The coefficients shown for negative $t$ apply to future values of $L$. The true lag distribution would have weight concentrated entirely at

9. Most manufacturing firms are on a weekly payroll period.

10. In "Discrete Approximations"; and Christopher A. Sims, "Approximate Specification in Distributed Lag Models," in International Statistical Institute, Proceedings of the 38th Session, 1971 (Bulletin of the International Statistical Institute, Vol. 44, August 1971), Pt. 1, pp. 285-94.

11. Technically, $L$ and $Y$ are assumed to be first-order Markov processes with very small parameters. 
zero; the biased lag distributions show weight spilling over to adjacent coefficients.

\begin{tabular}{lccl} 
& \multicolumn{3}{c}{$t$ (month) } \\
\cline { 2 - 4 } $\begin{array}{c}\text { Source of lag } \\
\text { distribution }\end{array}$ & -1 & 0 & \multicolumn{1}{c}{1} \\
Combined effects & 0.18 & 0.75 & 0.075 \\
Shift only & 0.10 & 0.90 & 0 \\
Aggregation only & 0.125 & 0.75 & 0.125
\end{tabular}

Note also that the sum of coefficients in the first row of the table is not exactly one. This is not rounding error, but an intrinsic feature of the analysis. In contrast to the unit averaging of data on both sides of a distributed lag equation, ${ }^{12}$ the asymmetric time aggregation of labor and output data destroys any exact connection between long-run effects in discrete and continuous data. One can show that so long as weekly $L$ is quite smooth, the bias from this source in sums of coefficients from distributed lag regressions of $Y$ on $L$ will be small.

Distributed lag regressions of labor on output will have their mean lag increased by 0.1 month by the time shift in the data and will include a bias toward local fluctuations generated by the tendency of the estimated lag distribution to correct for the greater smoothness of the output series. The above example for regressions of output on labor can be computed for regressions of labor on output, but such computations are somewhat less helpful here. The limiting forms of the lag distributions of labor on output will in general be complicated, reflecting the tendency to "unsmooth" $Y$; and the nature of the complications will depend on the unobservable weekly serial correlation patterns in output. Also, the sum of coefficients in this lag distribution will in general show greater bias than the other for a given degree of smoothness in the data. The following tabulation gives an example of the lag distribution for output on labor when the true relation is identity, on the same assumptions underlying the previous tabulation.

\begin{tabular}{ccccccccccc} 
& \multicolumn{110}{c}{$t$ (month) } \\
\cline { 2 - 11 } Coefficients & 0.00 & -4 & -3 & -2 & -1 & 0 & 1 & 2 & 3 \\
& 0.00 & -0.01 & 0.02 & -0.09 & 1.00 & 0.01 & 0.00 & 0.00
\end{tabular}

12. In which case the sum of the discrete lag distribution is the integral of the continuous lag distribution. 
All these sources of distortion from time aggregation cause little difficulty if the true lag distribution has a large mean and is itself very smooth. If the mean lag is several months, 0.1 month of bias one way or the other is not important.

When the adjustment of labor to output is rapid, as appears to be the case with manhours in response to production or sales in the empirical work reported below, the foregoing analysis suggests that the regressions of output on labor are better indicators of the true relation than are the regressions of labor on output. On the other hand, when the adjustment involves a long, smooth lag distribution, as appears to be the case in some of the empirical work with employment and production, time aggregation will produce little distortion in a regression of labor on output. Since in this case the corresponding lag distribution of output on labor will involve rapid oscillations or derivatives, time aggregation is likely to produce relatively greater distortions.

Many of the estimated lag distributions of output on labor discussed below indicate that a substantial proportion of the adjustment occurs within the contemporaneous month, and standard errors on them are small enough that the spurious coefficient on future labor in the lag distributions listed above would be statistically significant. Therefore, the estimated first future coefficient in lag regressions of output on labor is treated as part of the effect of current and lagged labor on output. ${ }^{13}$

While the biases discussed here would be less apparent with quarterly data, they would not necessarily be less misleading. The assumption of a locally very smooth output variable makes the bias in the reported sum of the coefficients for the regression of labor on output optimistically smallabout 7 percent. That bias would not be any smaller with quarterly data, though the suspicious oscillations in the coefficients of the lag distribution would disappear.

\section{Sources of Equation Error}

Although the theories of maximizing firm behavior considered thus far include stochastic elements, they derive exact relations between labor and

13. This is a reasonable procedure except in the case (which never arises here) in which the estimated first future coefficient is significantly larger than could be accounted for by this kind of leakage of contemporaneous effects. 
output. Least-squares estimates of the distributed lag regressions considered in the previous section would provide consistent estimates of the equations "biased by time aggregations, as discussed there. In at least some of the estimated equations, however, other sources of residual error affect results.

In empirical estimates using output as the dependent variable, results are similar using either deflated sales or the Federal Reserve industrial production index to measure output. When labor is the dependent variable in the regression, however, results with the two output variables are quite different. Labor is estimated as a two-sided, smooth distributed lag function of deflated sales, which does not fit into any natural behavioral story. One possible explanation is some source of pure measurement error in deflated sales that is substantially greater than any pure measurement error in the production index.

The sales data are compiled from a 5,000-firm subsample of the 65,000 firm sample used to generate the annual survey of manufactures. This is a substantially smaller sample than that used to obtain the employment data which, according to the same source, covers two-thirds of all employees in manufacturing. ${ }^{14}$ The sampling reliability of the production index varies by industry, but if it approaches that for employment, pure sampling error is at least a candidate for explaining the results.

Suppose that in the discrete data $L=Y$ for the data without sampling error, but that $Y^{*}$ is observed, where $Y^{*}=Y+e$ and $e$ is sampling error. ${ }^{15}$ If $e$ is serially uncorrelated, $Y$ is first-order Markov with parameter 0.9 in monthly discrete time, and $e$ has one-third the variance of $Y_{t}-0.9 Y_{t-1}$, then the form of the distributed lag regression of $L$ on observed $Y$ will be as follows: ${ }^{16}$

14. U.S. Bureau of Economic Analysis, 1973 Business Statistics, explanatory note 2 for p. 26 and note 1 for p. 73, respectively.

15. Since the sample of firms used is presumably not redrawn each month, there is no strong presumption that $e$ is serially uncorrelated.

16. If the true lag distribution in discrete time is something more complicated than the identity (a unit coefficient at zero), then the effect of the sampling error will be to convolute the true lag distribution with the lag distribution displayed in the text.

The lag distribution was obtained under the assumptions about the serial correlation properties of $Y$ and $e$, the sampling error, given in the text. The projection of $L=Y$ on $Y^{*}=Y+e$ is given by $H(L) H\left(L^{-1}\right) Y^{*}$, where $H(L)=g(L) /[g(L)+h(L)]$ and $Y=$ $g(L) u, e=h(L) v$, where $u$ and $v$ are independent "white noises," and $H, g$, and $h$ are polynomials in the lag operator $L$. 


\begin{tabular}{ccccccc}
\multicolumn{8}{c}{$t$ (month) } \\
\hline-3 & -2 & -1 & 0 & 1 & 2 & 3
\end{tabular}

$\begin{array}{llllllll}\text { Coefficient } & 0.00 & 0.03 & 0.13 & 0.67 & 0.13 & 0.03 & 0.00\end{array}$

Generally, as in this example, the effects of measurement error on an identity lag distribution will be symmetric about zero; and when the sampling error shows less positive serial correlation than the true component, the bias will be toward a smoothed lag distribution.

Equation error can arise from other sources, though none of those discussed below appears to be essential in explaining the observed results in this paper. (None can be decisively rejected, either, for that matter.)

Producers might make mistakes. If the output variable is exogenous at the industry level, errors made by firms must show up entirely in labor and be independent of output. If these errors had substantial variance, the effect would be similar to the effect of sampling error, but now in the $Y$ on $L$ rather than the $L$ on $Y$ distribution. Thus, where there is little evidence of two-sided lag distributions of $Y$ on $L$, this sort of optimization error is probably not very important.

Since output and labor data are always aggregated over industries and firms with different normal ratios of output to labor, and since the composition of the aggregates shifts over time, aggregation is undoubtedly a source of residual error in the output-labor relations. How it should affect the relations is unclear, a priori. As with any other general source of specification error, a substantial error of this kind is likely to distort the onesided form of a causal dynamic relation. Thus, the large number of acceptably one-sided relations found here may suggest that aggregation error is not a serious problem.

Fair, and Nadiri and Rosen, have explained regressions of labor on output in which coefficients on future output were significant by arguing that firms have knowledge of future output. ${ }^{17}$ Hirsch and Lovell have suggested that future output might be known well enough to make actual output a good measure of expectations. ${ }^{18}$ In regressions of labor on current and past output, forecasting by firms that is better than that obtainable from linear combinations of current and past output or labor data would cer-

17. Fair, Short-Run Demand for Workers and Hours; Nadiri and Rosen, Disequilibrium Model of Demand.

18. Albert A. Hirsch and Michael C. Lovell, Sales Anticipations and Inventory Behavior (Wiley, 1969). 
tainly be a source of equation error. However, where significant coefficients on future output do appear in the estimates reported below, it will be argued that the prescience of firms is not a convincing explanation.

Finally, the equations actually estimated are all log-linear, and are therefore only approximations to the linear relations that follow from the quadratic-linear theory discussed earlier. Since, in some industries, the estimated equations include data affected by strikes or by very sharp seasonals, the log-linear approximation could be a substantial source of specification error, but whether any systematic bias is likely to result from this source of error is difficult to determine a priori.

\section{SEASONALITY}

The theory discussed thus far does not in principle distinguish seasonal from nonseasonal movements in output and labor. In the empirical work the regressions have not been required to fit across seasonal and nonseasonal variation. The deterministic component of seasonal movementswhich can be captured in ordinary seasonal dummy variables-ought to be removed from the distributed lag regressions. The data are corrected for workdays per month on the output side, but not for variations in numbers of workdays due to major holidays, which are regarded as seasonal movements. Because of the asymmetric timing of the labor and output data, the result is that variations in output per month due to holidays may not be reflected in the unadjusted labor data, depending on what week of the month the holiday falls in. One working day is about 4 or 5 percent of a working month, and the residual standard error in the estimated equations is 1 percent to 2 percent. Thus, a regular tendency for Christmas to fall outside the sampled payroll period but for President's Day to fall within it would worsen the fit of the regression equation across seasonal frequencies. Since the location of the sampled pay period within the month, as well as that of some major holidays, shifts from year to year, not all of the distortion in the labor-output relation arising from major holidays will be confined to the deterministic component of the seasonal.

Even in the absence of distortion in the underlying relation except at the deterministic seasonal frequencies, equations of the form estimated in this paper could still run into problems arising from the attempts of firms to anticipate slowly evolving seasonal movements in output.

To capture the likely form of firms' projections of seasonal movements 
in output would require estimation of lag distributions considerably longer than those reported below. But to do this appropriately, allowing a flexible form to the seasonal components of the lag distribution, is beyond the scope of this paper.

\section{THE DATA}

Estimates were made with data for all manufacturing, for durables and nondurables, and for three two-digit level industries for which physical production measures are available: primary metals, apparel, and paper. ${ }^{19}$ In all industries, two labor variables were considered-manhours and employment of production workers. The Federal Reserve index of industrial production was an output variable in all industries. In addition, for total manufacturing, shipments deflated by the wholesale price index for manufacturing was used as an alternative output variable (called "sales"). ${ }^{20}$ All data were collected in seasonally unadjusted form. The statistical procedures used included a kind of seasonal adjustment as one step of the analysis.

For data up to 1963, a substantial part of the Federal Reserve index for total manufacturing estimates "production" from manhour data. In these estimates, a judgmental allowance was made for the possibility that SRIRL exists; but the allowances appear to be small and rare enough that the main effect of using manhour data would be to bias regression estimates toward an identity relation between the labor and production series. ${ }^{21}$ Fortunately, cross-checks on results using other data are available.

In this study, such independent cross-checks are provided by the sales

19. Production data for the petroleum industry are directly measured in the Federal Reserve Board index. However, initial estimates for this paper turned up a residual of 10 standard deviations for the January 1969 observation, corresponding to a short strike, whose timing was such that it had maximum effect on the payroll reporting period of the Bureau of Labor Statistics. New results, using a strike dummy variable, eliminated the January 1969 problem but turned up two new outliers of 3.5 standard deviations each. Apparently, output-labor relations in the petroleum industry have highly non-normal residuals, so that least-squares methods probably are not applicable.

20. At an earlier stage of the research, experiments were made with sales corrected for changes in inventories of finished goods as an output variable. Results differed little from those with sales itself, and since such data are available for only a restricted period, the experiments were not pursued.

21. The official description of the series is given in Board of Governors of the Federal Reserve System, Industrial Production, 1971 Edition (1972). 
data, which are collected independently of the payroll data, and by the use of two-digit subindustries for which FRB output is measured directly from production volumes, at least in the most recent years. As an added check, regressions were tested for temporal homogeneity, with the sample split at March 1961. The last half of the sample thus contains much less interpolation from manhour data than does the earlier half. If bias from this source were serious, one would expect a substantial shift in coefficients between the two components of the sample for total manufacturing, durables, and nondurables; and in fact such shifts do occur. The shift is marginally significant at the 10 percent confidence level in total manufacturing and significant at the 5 percent confidence level in durables and nondurables, for regressions of output on manhours. In all cases the shift is in the expected direction, showing a decline in the sum of coefficients on contemporaneous and first leading values of manhours between the subperiods. The decline is from 1.29 to 1.13 for durables, from 1.20 to 0.97 for total manufacturing, and from 0.73 to 0.62 for nondurables. Some bias in the results for aggregate manufacturing seems likely from this source, therefore, but its absolute magnitude is moderate. ${ }^{22}$

The basic data used cover the period 1947-73. Two years at the beginning of the sample and one at the end are lost to leads and lags in the regressions. In addition, two months at the beginning are lost to prefiltering and an additional twelve months are dropped at each end of the series because of the unreliability of deseasonalization at the ends of the series. Thus the actual regressions cover the sample period March 1950 through December 1971.

\section{Statistical Procedures}

The basic statistical model of this study makes the logarithm of the dependent variable a linear function of twelve future values, the current value, and twenty-four past values of the logarithm of the independent variable, plus a constant and a trend term, with a residual error independent of the regressors. These assumptions impose only weak restrictions on the struc-

22. An interesting fact noted too late for adequate investigation is that the last-half results for all three aggregates fit the hypothesis that all adjustment of manhours to output occurs within the contemporaneous month. The significant lags in adjustment in the full-sample regression arise solely from the pre-1963 portion of the sample. 
ture generating the time series on output and labor. For example, if the data were generated by a two-equation system and involved exogenous variables not included in these regressions, under general assumptions there would still be two-sided distributed lag regressions of output and labor on each other (involving past and future coefficients) with residuals independent of the right-hand variable. Though in this case neither regression would in general be a structural equation, statistical inference about the coefficients would in itself be accurate. In particular, a test of the hypothesis that future coefficients are zero, which can be regarded as a test of the hypothesis that the equation is in fact a structural equation, will be valid. The basic statistical model would be substantially misspecified only if the covariance properties of the variables were temporally unstable or if the restriction of twelve leads and twenty-four lags was seriously mistaken.

In the central set of estimates, a procedure described and justified at length elsewhere is applied. ${ }^{23}$ The aim is to correct for serial correlation in the residuals without any strong prior restriction on the parametric form of the serial correlation, and also to eliminate from the data variation in a band about the seasonal frequencies. The latter part of the procedure is a form of seasonal "overadjustment," aimed at allowing for possible effects on the data of a slowly evolving seasonal pattern of "noise," or errors in variables. ${ }^{24}$

The theoretical models discussed above generate exact dynamic relations between labor and current and past output. If, as is quite possible, those

23. Christopher A. Sims, "Seasonality in Regression," Journal of the American Statistical Association, Vol. 69 (September 1974), pp. 618-26.

24. Logarithms of the basic data are taken, and each series is prefiltered through the filter $(1-.9 L)^{2}$, where $L$ is the lag operator. Mean, linear trend, and a deterministic seasonal pattern are removed by ordinary-least-squares (OLS) regression. The resulting series are Fourier-transformed, using 768 points over the $(-\pi, \pi)$ interval and fifteen Fourier transform ordinates are set to zero in a band centered at each of the eleven seasonal frequencies. (The width of the band is thus approximately $\pi / 26$.) The data are then inverse-Fourier-transformed and the basic regression estimated over the sample shortened as indicated above. The residuals from this first estimate of the regression are Fourier-transformed, the spectral density estimated using a smoothing window triangular with base 26 ordinates (about $\pi / 15$, or 11 harmonic frequencies at the base; effective degrees of freedom about 18). The smoothed estimates at the edges of the seasonal bands are corrected for the downward bias due to the erasure of variance in the seasonal bands. The original Fourier-transformed data, with seasonal bands erased, are divided by the square root of the estimated residual spectral density and inverse-Fouriertransformed. Then the final, efficient, regression estimates are obtained by OLS. Appendix Table A-1 presents results of tests of the hypothesis that regressions fit seasonally. 
dynamic relations have one-sided inverses, they can be written equally well as relations of output to current and past labor. Since the relations derived in the theory are exact, the theory suggests, if anything, that regressions in either direction will recover the true dynamics, even though in a certain intuitive sense the theory takes industry output as exogenous to decisionmakers. Many possible sources of significant coefficients on future values of the independent variable in two-sided regressions have been suggested earlier in this paper. However, with the exception of a fairly small significant positive coefficient on the first future value of labor in explaining output, ${ }^{25}$ finding significant coefficients on future values of the independent variable would suggest that the estimates are seriously biased or that the central economic models of this paper are not useful ways to rationalize the results. Hence, a critical specification test for each of the regressions concerns whether the twelve future coefficients (or eleven, excluding the first future coefficient, with labor on the right-hand side) are zero. If the behavioral relation of interest involves no nonzero future coefficients, this procedure constitutes a test for the null hypothesis that the independent variable is statistically exogenous. Only in this case can the estimated lag distributions be considered estimates of the behavioral relation. ${ }^{26}$

\section{Results}

\section{MANHOURS}

Tables 1 and 2 present estimates of lag distributions from regressions of manhours and output on each other. Table 3 presents the cumulative relations between output and labor obtained by summing these lagged coefficients over varying intervals. The results presented are for regressions in

25. Which, recall, might be expected to arise from the special form of time aggregation in manufacturing labor and output data.

26. This was pointed out in Christopher A. Sims, "Money, Income, and Causality," American Economic Review, Vol. 62 (September 1972), pp. 540-52. The test is also a test of the null hypothesis that the independent variable "causes" the dependent variable in the sense defined by C. W. J. Granger in "Investigating Causal Relations by Econometric Models and Cross-Spectral Methods," Econometrica, Vol. 37 (July 1969), pp. 424-38. Granger's terminology is a useful verbal shorthand and a guide to intuition if one already grasps what statistical exogeneity means. However, the word "cause" has such a variety of meanings that to attempt to reach an understanding of statistical exogeneity by translating it into Granger's causal terminology can be counterproductive. 
Table 1. Lag Distributions and Summary Statistics, Regressions of Manhours on Output, Selected Manufacturing Industries, Sample Period March 1950-December 1971

\begin{tabular}{|c|c|c|c|c|c|c|c|}
\hline \multirow{2}{*}{$\begin{array}{c}\text { Lag } \\
\text { (month) } \\
\text { and } \\
\text { summary } \\
\text { statistic }\end{array}$} & \multicolumn{2}{|c|}{ Total manufacturing } & \multirow[b]{2}{*}{$\begin{array}{c}\text { Durable } \\
\text { goods }\end{array}$} & \multirow[b]{2}{*}{$\begin{array}{l}\text { Non- } \\
\text { durable } \\
\text { goods }\end{array}$} & \multirow[b]{2}{*}{ Paper } & \multirow[b]{2}{*}{$\begin{array}{c}\text { Primary } \\
\text { metals }\end{array}$} & \multirow[b]{2}{*}{ Apparel } \\
\hline & $\begin{array}{c}\text { Index of } \\
\text { industrial } \\
\text { production }\end{array}$ & Sales $^{\mathrm{a}}$ & & & & & \\
\hline-12 & $\ldots$ & -0.099 & $\cdots$ & $\cdots$ & $\cdots$ & $\cdots$ & $\cdots$ \\
\hline-11 & $\ldots$ & 0.044 & $\ldots$ & ... & .. & $\cdots$ & $\cdots$ \\
\hline-10 & $\ldots$ & -0.016 & $\ldots$ & $\ldots$ & $\cdots$ & $\cdots$ & .. \\
\hline-9 & $\ldots$ & 0.015 & $\ldots$ & $\ldots$ & ... & $\ldots$ & ... \\
\hline-8 & $\ldots$ & -0.002 & $\ldots$ & $\ldots$ & $\ldots$ & $\ldots$ & ... \\
\hline-7 & $\ldots$ & 0.039 & $\ldots$ & $\ldots$ & $\ldots$ & $\ldots$ & $\cdots$ \\
\hline-6 & $\ldots$ & -0.031 & $\ldots$ & ... & $\cdots$ & $\cdots$ & $\cdots$ \\
\hline-5 & $\ldots$ & 0.012 & $\ldots$ & ... & .. & $\ldots$ & $\ldots$ \\
\hline-4 & $\ldots$ & 0.044 & ... & $\ldots$ & $\ldots$ & $\ldots$ & $\ldots$ \\
\hline-3 & $\ldots$ & -0.007 & $\ldots$ & ... & $\ldots$ & $\ldots$ & $\ldots$ \\
\hline-2 & $\ldots$ & 0.130 & $\ldots$ & $\ldots$ & $\ldots$ & $\ldots$ & $\ldots$ \\
\hline-1 & -0.006 & 0.114 & -0.032 & 0.039 & 0.092 & 0.006 & 0.099 \\
\hline 0 & 0.698 & 0.347 & 0.740 & 0.551 & 0.267 & 0.644 & 0.312 \\
\hline 1 & 0.132 & 0.129 & 0.062 & 0.202 & 0.137 & 0.006 & 0.165 \\
\hline 2 & -0.022 & 0.099 & -0.008 & 0.075 & 0.077 & 0.058 & 0.101 \\
\hline 3 & 0.030 & 0.071 & 0.028 & 0.050 & 0.021 & -0.013 & 0.048 \\
\hline 4 & 0.044 & 0.096 & 0.048 & 0.064 & 0.009 & 0.037 & 0.049 \\
\hline 5 & 0.020 & 0.036 & 0.031 & 0.011 & 0.011 & 0.035 & 0.042 \\
\hline 6 & 0.062 & 0.052 & 0.036 & 0.092 & -0.021 & 0.021 & 0.136 \\
\hline 7 & -0.025 & 0.020 & -0.024 & -0.040 & 0.024 & 0.008 & -0.002 \\
\hline 8 & 0.021 & 0.034 & 0.010 & -0.017 & 0.025 & 0.012 & -0.046 \\
\hline 9 & -0.043 & 0.019 & -0.024 & -0.032 & 0.004 & 0.010 & -0.050 \\
\hline 10 & 0.126 & 0.053 & 0.095 & 0.114 & -0.026 & 0.021 & 0.053 \\
\hline 11 & -0.085 & -0.012 & -0.072 & -0.040 & -0.026 & 0.018 & 0.042 \\
\hline 12 & -0.047 & -0.091 & 0.015 & -0.023 & 0.017 & 0.000 & -0.061 \\
\hline$\sum 13-24$ & 0.029 & -0.080 & -0.021 & 0.045 & 0.003 & 0.019 & -0.075 \\
\hline
\end{tabular}

Standard

error of

$\begin{array}{llllllll}\sum 13-24 & 0.056 & 0.126 & 0.048 & 0.093 & 0.024 & 0.063 & 0.119\end{array}$

Standard

error of

coeffi-

cient

\begin{tabular}{clllllll} 
Largest & 0.037 & 0.039 & 0.027 & 0.052 & 0.033 & 0.017 & 0.042 \\
Smallest & 0.032 & 0.036 & 0.024 & 0.047 & 0.028 & 0.016 & 0.040 \\
$R^{2}$ & 0.8869 & 0.5895 & 0.9139 & 0.7958 & 0.6049 & 0.9371 & 0.6077 \\
\hline
\end{tabular}

Sources: Author's regressions, discussed in the text, using information described in the data section of the text.

a. Shipments deflated by the wholesale price index for manufacturing. 
Table 2. Lag Distributions and Summary Statistics, Regressions of Output on Manhours, Selected Manufacturing Industries, Sample Period March 1950-December 1971

\begin{tabular}{|c|c|c|c|c|c|c|c|}
\hline \multirow{2}{*}{$\begin{array}{c}\text { Lag } \\
\text { (month) } \\
\text { and } \\
\text { summary } \\
\text { statistic }\end{array}$} & \multicolumn{2}{|c|}{ Total manufacturing } & \multirow[b]{2}{*}{$\begin{array}{l}\text { Durable } \\
\text { goods }\end{array}$} & \multirow[b]{2}{*}{$\begin{array}{c}\text { Non- } \\
\text { durable } \\
\text { goods }\end{array}$} & \multirow[b]{2}{*}{ Paper } & \multirow[b]{2}{*}{$\begin{array}{l}\text { Primary } \\
\text { metals }\end{array}$} & \multirow[b]{2}{*}{ Apparel } \\
\hline & $\begin{array}{l}\text { Index of } \\
\text { industrial } \\
\text { production }\end{array}$ & Sales $^{\mathbf{a}}$ & & & & & \\
\hline-1 & 0.167 & 0.116 & 0.144 & 0.219 & 0.342 & 0.046 & 0.198 \\
\hline 0 & 0.949 & 0.890 & 1.075 & 0.583 & 0.713 & 1.376 & 0.519 \\
\hline 1 & 0.037 & 0.100 & 0.029 & 0.032 & 0.042 & 0.053 & 0.079 \\
\hline 2 & 0.049 & 0.094 & 0.005 & 0.036 & 0.042 & -0.111 & 0.018 \\
\hline 3 & -0.071 & -0.278 & -0.046 & -0.059 & 0.111 & 0.014 & -0.176 \\
\hline 4 & -0.070 & -0.029 & -0.100 & -0.041 & 0.082 & -0.105 & 0.096 \\
\hline 5 & -0.040 & -0.009 & -0.046 & 0.003 & -0.308 & -0.056 & -0.027 \\
\hline 6 & -0.056 & -0.147 & -0.033 & -0.057 & -0.009 & -0.024 & -0.173 \\
\hline 7 & 0.028 & 0.164 & 0.029 & 0.018 & -0.040 & -0.025 & -0.020 \\
\hline 8 & -0.024 & -0.098 & 0.007 & -0.064 & -0.035 & -0.019 & 0.024 \\
\hline 9 & 0.003 & -0.078 & -0.004 & 0.035 & 0.104 & -0.009 & -0.024 \\
\hline 10 & -0.035 & -0.026 & -0.025 & -0.046 & 0.261 & -0.023 & -0.101 \\
\hline 11 & 0.050 & 0.178 & 0.036 & 0.112 & -0.171 & -0.049 & 0.155 \\
\hline 12 & -0.041 & 0.031 & -0.071 & -0.102 & -0.357 & -0.002 & -0.153 \\
\hline$\sum 13-24$ & -0.049 & -0.102 & 0.025 & -0.266 & -0.307 & -0.028 & -0.327 \\
\hline $\begin{array}{l}\text { Standard } \\
\text { error of }\end{array}$ & f & 116 & 0 & & & & \\
\hline $\begin{array}{l}\text { Standard } \\
\text { error of } \\
\text { coeffi- } \\
\text { cient }\end{array}$ & f & 0.116 & 0.050 & 0.124 & 0.188 & 0.130 & 0.254 \\
\hline Largest & 0.051 & 0.112 & 0.040 & 0.067 & 0.125 & 0.034 & 0.111 \\
\hline Smallest & 0.044 & 0.092 & 0.036 & 0.060 & 0.118 & 0.031 & 0.088 \\
\hline$R^{2}$ & 0.8761 & 0.6461 & 0.9161 & 0.6216 & 0.6044 & 0.9334 & 0.4060 \\
\hline
\end{tabular}

Sources: See Table 1.

a. Shipments deflated by the wholesale price index for manufacturing.

which coefficients on lags -2 through -12 (the second through twelfth future coefficients) were constrained to be zero, except where the null hypothesis that these coefficients were zero was rejected (for output on manhours) or the null hypothesis that all twelve future coefficients were zero was rejected (for manhours on output). As appendix Table A-2 demonstrates, in a majority of the industries the exogeneity test rejects neither direction of regression. For the paper industry and for total manufacturing with deflated sales as the output variable, the twelve future coefficients are 


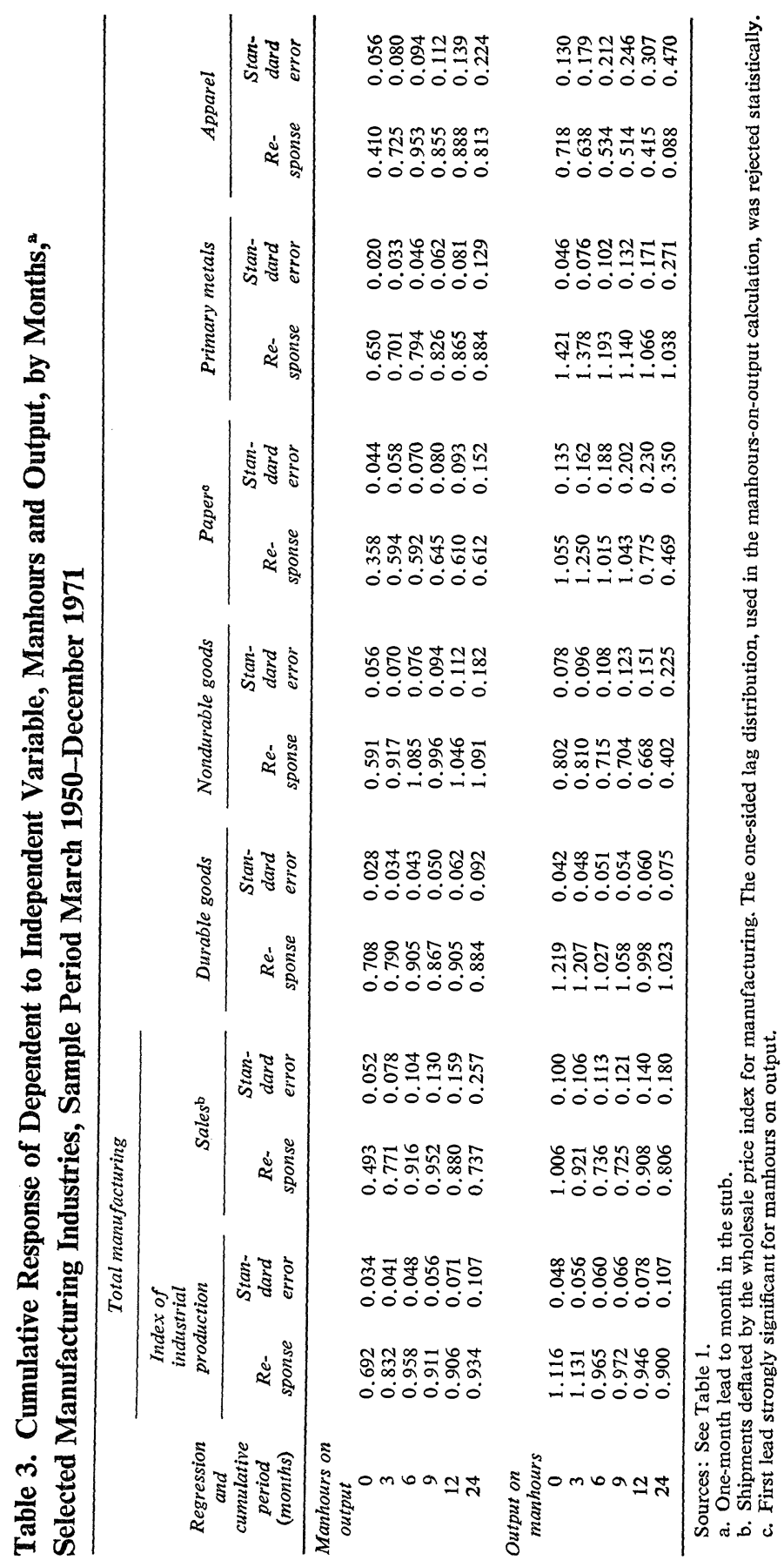


significantly different from zero when output is the independent variable. In no case are the eleven future coefficients significantly different from zero in regressions of output on manhours (though the results for nondurables are suspect on this score). Though the first future coefficient in these regressions is strongly significant in several industries, the coefficient is never any larger than can be accounted for by time-aggregation bias of the type discussed above.

Except where the exogeneity test rejects one direction of regression, results are broadly consistent under either direction. Some degree of SRIRL, for at least a short time interval, seems likely in all the industries reported in Table 3 except the regressions of output on manhours for apparel and nondurable goods. (In assessing this conclusion, remember that the zeroorder results of output on manhours are slightly biased toward zero by aggregation over time.) In all cases except output on manhours for paper and apparel the cumulative response over six months is estimated with a standard error of 0.11 or less, and in all cases a one-standard-error band about the six-month response overlaps one-standard-error bands about the twelve- and twenty-four month responses. Appendix Table A-3 demonstrates that the large zero-order coefficients in these lag distributions are not the whole story. But there is little evidence that the dynamics require more than six months to work themselves out; and by the end of six months, there is much less evidence of SRIRL in the regression results.

Only for primary metals do regressions in both directions offer firm evidence that a less than proportional response of manhours to output persists through the whole six-month adjustment period for either direction of regression. For durables, the regression of manhours on output shows significant, though small, SRIRL at six and twelve months, but the regression in the other direction, which also passes an exogeneity test, shows none at all. SRIRL of this magnitude could easily result entirely from temporal aggregation bias. On the other hand, because of the increasing standard errors on the longer-run responses, even for primary metals the results cannot rule out constant or diminishing returns to labor over twelve or twenty-four months. ${ }^{27}$

For apparel, the regression of output on manhours shows significant

27. At a late stage of the work for this paper I found one very large residual (around 4.5 standard errors for August 1959) for primary metals that probably deserves the same treatment given the even more implausible January 1969 petroleum residual. Thus all the results for primary metals should be treated with some skepticism. 
decreasing returns to labor at six, twelve, and twenty-four months. However, in both directions of regression, the standard errors for apparel are the largest for all the industries, and the $F$-test results for exogeneity in Table A-3 are marginal. Probably neither direction of regression for this industry gives reliable results, and the exogeneity tests have been passed by virtue of the poor fit of the equations. For the paper industry, the six-, twelve-, and twenty-four-month responses of manhours to output are very significantly less than one, but this regression fails to pass the exogeneity test due to the presence of a first future coefficient 34 percent as large as the zero-order coefficient (Table 1). The regression for output on manhours in the industry does not reveal SRIRL at six months.

\section{EMPLOYMENT}

Tables 4 through 6, corresponding to Tables 1 through 3 in the outputmanhours regressions, show that the initial response of employment to output, over the first month or two, is much smaller than the response of manhours. As appendix Table A-4 shows, in three industries, regressions of output on employment fail the exogeneity test. Standard errors on coefficients are much larger in regressions of output on employment than they are in those of output on manhours.

The tendency for the regressions of output on employment to perform poorly has two natural explanations. First, since the ratio of employment to output can undoubtedly be varied in the short run with less inefficiency than would accompany a similar variation in the ratio of manhours to output, employment might be relatively more affected by variables not accounted for in the model. Second, because employment responds slowly and smoothly to output changes, it might be impossible to determine current output from current and past employment. ${ }^{28}$

As before, one-standard-error bands about the six-month responses overlap one-standard-error bands about twelve- and twenty-four-month responses except for the regression of total manufacturing employment on

28. Technically, the lag distribution of employment on output might not be invertible. If, as is true with many of the lag distributions for manhours on output, the zero-order coefficient is larger in absolute value than the sum of the absolute values of the remaining coefficients, the lag distribution automatically has a one-sided inverse. Except for durable goods and primary metals, the estimated regressions of employment on output come nowhere near meeting this sufficient condition for invertibility. 
Table 4. Lag Distributions and Summary Statistics, Regressions of Employment on Output, Selected Manufacturing Industries, Sample Period March 1950-December 1971

\begin{tabular}{|c|c|c|c|c|c|c|c|}
\hline \multirow{2}{*}{$\begin{array}{c}\text { Lag } \\
\text { (month) } \\
\text { and } \\
\text { summary } \\
\text { statistic }\end{array}$} & \multicolumn{2}{|c|}{ Total manufacturing } & \multirow[b]{2}{*}{$\begin{array}{l}\text { Durable } \\
\text { goods }\end{array}$} & \multirow[b]{2}{*}{$\begin{array}{l}\text { Non- } \\
\text { durable } \\
\text { goods }\end{array}$} & \multirow[b]{2}{*}{ Paper } & \multirow[b]{2}{*}{$\begin{array}{c}\text { Primary } \\
\text { metals }\end{array}$} & \multirow[b]{2}{*}{ Apparel } \\
\hline & $\begin{array}{c}\text { Index of } \\
\text { industrial } \\
\text { production }\end{array}$ & Sales $^{\mathbf{a}}$ & & & & & \\
\hline-12 & $\ldots$ & -0.048 & $\ldots$ & $\cdots$ & ... & $\cdots$ & $\cdots$ \\
\hline-11 & $\ldots$ & 0.003 & $\ldots$ & $\ldots$ & $\ldots$ & $\ldots$ & $\ldots$ \\
\hline-10 & $\ldots$ & -0.005 & $\ldots$ & $\ldots$ & $\ldots$ & $\ldots$ & $\ldots$ \\
\hline-9 & $\ldots$ & -0.001 & $\ldots$ & $\ldots$ & $\ldots$ & $\ldots$ & $\ldots$ \\
\hline-8 & $\ldots$ & -0.008 & $\ldots$ & $\ldots$ & $\ldots$ & $\ldots$ & $\ldots$ \\
\hline-7 & $\ldots$ & 0.027 & $\ldots$ & $\ldots$ & $\ldots$ & $\ldots$ & $\ldots$ \\
\hline-6 & $\ldots$ & -0.006 & $\ldots$ & $\ldots$ & $\ldots$ & $\ldots$ & $\ldots$ \\
\hline-5 & $\ldots$ & -0.005 & $\ldots$ & $\ldots$ & $\ldots$ & $\ldots$ & $\ldots$ \\
\hline-4 & $\ldots$ & -0.008 & $\ldots$ & $\ldots$ & $\ldots$ & $\ldots$ & $\ldots$ \\
\hline-3 & $\ldots$ & 0.015 & $\ldots$ & $\ldots$ & $\ldots$ & $\ldots$ & $\ldots$ \\
\hline-2 & $\ldots$ & 0.063 & $\ldots$ & $\ldots$ & $\ldots$ & $\ldots$ & $\ldots$ \\
\hline-1 & -0.003 & 0.087 & -0.008 & 0.029 & 0.030 & -0.023 & 0.075 \\
\hline 0 & 0.486 & 0.287 & 0.570 & 0.224 & 0.124 & 0.620 & 0.158 \\
\hline 1 & 0.084 & 0.074 & 0.029 & 0.192 & 0.085 & -0.021 & 0.142 \\
\hline 2 & 0.087 & 0.121 & 0.071 & 0.092 & 0.102 & 0.078 & 0.069 \\
\hline 3 & 0.019 & 0.062 & 0.010 & 0.021 & 0.011 & -0.030 & 0.007 \\
\hline 4 & 0.036 & 0.082 & 0.044 & 0.077 & 0.034 & 0.056 & 0.056 \\
\hline 5 & 0.081 & 0.052 & 0.075 & 0.060 & 0.024 & 0.033 & 0.046 \\
\hline 6 & -0.003 & 0.036 & 0.025 & 0.018 & -0.022 & 0.047 & 0.054 \\
\hline 7 & -0.003 & 0.044 & -0.023 & 0.013 & 0.044 & 0.008 & 0.032 \\
\hline 8 & 0.042 & 0.015 & 0.029 & 0.002 & 0.023 & 0.025 & 0.014 \\
\hline 9 & -0.022 & 0.047 & -0.017 & -0.024 & 0.008 & 0.029 & 0.012 \\
\hline 10 & 0.121 & 0.032 & 0.087 & 0.081 & -0.009 & 0.030 & 0.025 \\
\hline 11 & -0.068 & 0.022 & -0.048 & 0.016 & -0.001 & 0.032 & 0.037 \\
\hline 12 & 0.020 & -0.019 & 0.036 & 0.006 & 0.038 & 0.013 & -0.005 \\
\hline$\sum 13-24$ & 0.050 & 0.025 & 0.021 & -0.024 & -0.017 & 0.120 & -0.043 \\
\hline
\end{tabular}

Standard

error of

$\begin{array}{llllllll}\sum 13-24 & 0.041 & 0.087 & 0.033 & 0.070 & 0.055 & 0.095 & 0.076\end{array}$

Standard

error of

coeffi-

cient

Largest

Smallest

$$
0.034
$$

0.029

0.032

0.024

0.019

0.023

0.020 $R^{2}$

0.028
0.8949

0.026

0.028

0.023

0.017

0.020

0.018

Sources: See Table 1.

a. Shipments deflated by the wholesale price index for manufacturing. 
Table 5. Lag Distributions and Summary Statistics, Regressions of Output on Employment, Selected Manufacturing Industries, Sample Period March 1950-December 1971

\begin{tabular}{|c|c|c|c|c|c|c|c|}
\hline \multirow{2}{*}{$\begin{array}{c}\text { Lag } \\
\text { (month) } \\
\text { and } \\
\text { summary } \\
\text { statistic }\end{array}$} & \multicolumn{2}{|c|}{ Total manufacturing } & \multirow[b]{2}{*}{$\begin{array}{l}\text { Durable } \\
\text { goods }\end{array}$} & \multirow[b]{2}{*}{$\begin{array}{l}\text { Non- } \\
\text { durable } \\
\text { goods }\end{array}$} & \multirow[b]{2}{*}{ Paper } & \multirow[b]{2}{*}{$\begin{array}{c}\text { Primary } \\
\text { metals }\end{array}$} & \multirow[b]{2}{*}{ Apparel } \\
\hline & $\begin{array}{c}\text { Index of } \\
\text { industrial } \\
\text { production }\end{array}$ & Sales $^{\mathrm{a}}$ & & & & & \\
\hline-12 & $\ldots$ & $\ldots$ & $\ldots$ & -0.107 & -0.301 & -0.051 & $\ldots$ \\
\hline-11 & $\ldots$ & $\ldots$ & $\ldots$ & -0.003 & 0.181 & 0.034 & $\ldots$ \\
\hline-10 & $\ldots$ & $\ldots$ & $\ldots$ & 0.290 & -0.282 & -0.023 & $\ldots$ \\
\hline-9 & $\ldots$ & $\ldots$ & $\ldots$ & -0.334 & -0.107 & 0.060 & $\ldots$ \\
\hline-8 & $\ldots$ & $\ldots$ & $\ldots$ & 0.095 & 0.381 & 0.029 & $\ldots$ \\
\hline-7 & $\ldots$ & $\ldots$ & $\ldots$ & -0.073 & 0.198 & -0.049 & $\ldots$ \\
\hline-6 & $\ldots$ & $\ldots$ & $\ldots$ & -0.141 & -0.516 & 0.048 & $\ldots$ \\
\hline-5 & $\ldots$ & $\ldots$ & $\ldots$ & 0.210 & 0.091 & 0.038 & $\ldots$ \\
\hline-4 & $\ldots$ & $\ldots$ & $\ldots$ & 0.271 & 0.645 & -0.089 & $\ldots$ \\
\hline-3 & $\ldots$ & $\ldots$ & $\ldots$ & -0.106 & -0.401 & 0.106 & $\ldots$ \\
\hline-2 & $\ldots$ & $\ldots$ & $\ldots$ & 0.195 & 0.827 & 0.175 & $\ldots$ \\
\hline-1 & 0.257 & 0.062 & 0.226 & 0.599 & 0.483 & 0.079 & 0.493 \\
\hline 0 & 1.178 & 1.393 & 1.201 & 0.775 & 0.388 & 1.333 & 1.006 \\
\hline 1 & 0.151 & 0.071 & 0.173 & -0.171 & -0.055 & 0.177 & 0.274 \\
\hline 2 & -0.182 & -0.132 & -0.140 & -0.100 & 0.093 & -0.118 & -0.376 \\
\hline 3 & -0.108 & -0.189 & -0.085 & -0.139 & -0.167 & -0.004 & -0.368 \\
\hline 4 & -0.087 & -0.239 & -0.101 & 0.009 & 0.278 & -0.143 & 0.402 \\
\hline 5 & -0.217 & -0.117 & -0.168 & -0.129 & -0.567 & -0.082 & -0.383 \\
\hline 6 & 0.034 & 0.028 & -0.022 & -0.361 & -0.368 & -0.046 & -0.340 \\
\hline 7 & 0.085 & 0.124 & 0.063 & 0.077 & -0.102 & -0.035 & 0.213 \\
\hline 8 & -0.053 & -0.094 & -0.023 & 0.133 & 0.431 & -0.079 & -0.215 \\
\hline 9 & -0.111 & -0.125 & -0.033 & 0.032 & -0.330 & -0.027 & -0.029 \\
\hline 10 & 0.012 & -0.107 & -0.004 & 0.002 & 0.439 & 0.019 & 0.124 \\
\hline 11 & -0.042 & 0.217 & -0.003 & -0.020 & -0.143 & -0.093 & -0.297 \\
\hline 12 & -0.091 & 0.065 & -0.121 & -0.107 & -1.005 & -0.089 & -0.038 \\
\hline$\sum 13-24$ & -0.139 & -0.181 & -0.014 & -0.478 & -0.327 & -0.172 & -0.200 \\
\hline \multicolumn{8}{|c|}{$\begin{array}{l}\text { Standard } \\
\text { error of }\end{array}$} \\
\hline $\begin{array}{c}\sum 13-2 \\
\text { Standard } \\
\text { error o } \\
\text { coeffi- } \\
\text { cient }\end{array}$ & $\begin{array}{l}40.122 \\
f\end{array}$ & 0.139 & 0.090 & 0.329 & 0.734 & 0.266 & 0.333 \\
\hline Largest & 0.076 & 0.141 & 0.061 & 0.151 & 0.299 & 0.063 & 0.210 \\
\hline Smallest & 0.067 & 0.118 & 0.053 & 0.111 & 0.234 & 0.049 & 0.184 \\
\hline$R^{2}$ & 0.7933 & 0.6665 & 0.8652 & 0.6694 & 0.4877 & 0.9036 & 0.5517 \\
\hline
\end{tabular}

Sources: See Table 1.

a. Shipments deflated by the wholesale price index for manufacturing. 


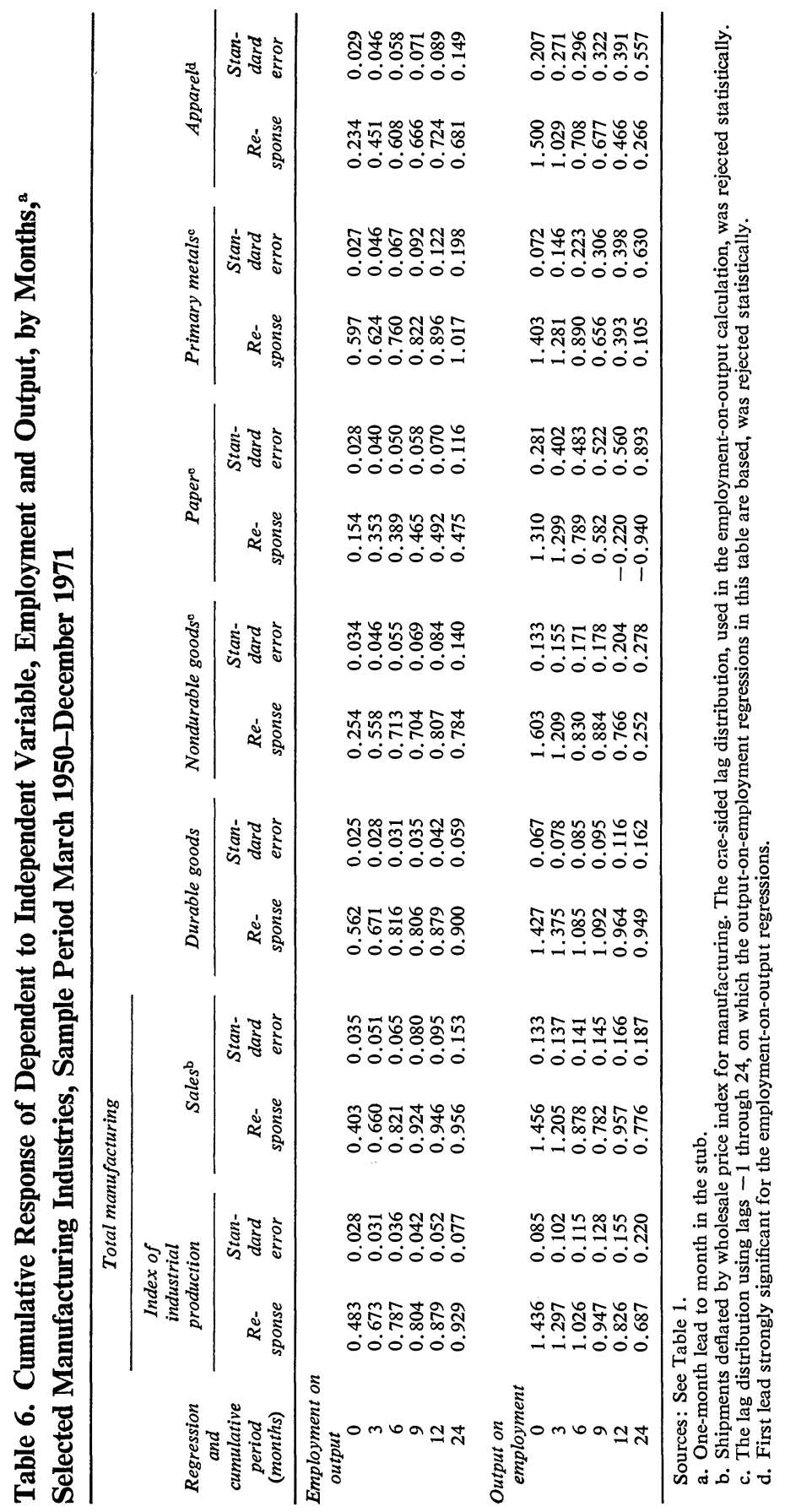


FRB production. Nonetheless, the persistent rise in total response from the sixth through the twelfth month in all regressions of employment on output makes it likely, if not proven, that some adjustment of employment to output persists beyond six months. Changes in total response between the twelfth and twenty-fourth months in these regressions are all insignificant and small, and the signs are inconsistent. It seems reasonable to conclude that the adjustment of employment to output is virtually complete within a year.

In contrast to the manhours results, the evidence for less than proportional response of employment to output over six months is strong in every industry in the regression of employment on output. This pattern persists in most industries for the twelve-month response as well. However, while the six-month responses are clearly smaller for employment than manhours in each industry except primary metals, the differences in the twelve-month responses of the two labor variables are probably not statistically significant.

The more rapid and thoroughgoing response of manhours than of employment to output changes supports the presumption that hours per worker are more freely variable than is the number of workers. In fact, because of the logarithmic form of the regressions, the difference in coefficients between the equations for manhours on output and for employment on output gives estimates of the regression of hours per man on output. For all but the suspect results for primary metals, the largest coefficient in these implicit regressions is in the contemporaneous month and is positive. In the industries for which regressions of employment on output show SRIRL persisting even over twelve and twenty-four months while the regressions of manhours on output do not, sums of the coefficients of these implicit hours-perman equations will be positive, implying that part of the effect of output on hours is "permanent."

\section{Findings of Other Studies}

The principal finding of this paper-that manhours adjust about in proportion to an output change within six months-can be compared with some of the previous empirical work on short-run demand for labor. Other studies support the present finding that the lag in adjustment of manhours 
to output is short; but most do not agree that the adjustment is fully proportionate.

Wilson and Eckstein studied manhours of production workers for total manufacturing. ${ }^{29}$ Their speed of adjustment turns out to vary with a dating variable, which implies an elasticity of manhours with respect to output after six months of 1.06 when time is set at 1948 and of 0.82 when time is set at 1961. Taking a rough average, their six-month elasticity is $0.94 .^{30}$ Their long-run elasticity is 1.15 in 1948 and 0.87 in 1961, with a rough average of 1.01. Nadiri and Rosen offer estimates for all manufacturing production workers, using deflated sales to measure output. ${ }^{31}$ After six months, their estimated elasticity of manhours with respect to sales is 0.89 , indicating a rapid and almost proportional response. However, they estimate a long, continuing, adjustment that eventually reduces the long-run elasticity to about 0.6 . F. P. R. Brechling, studying British manufacturing and apparently using total manhours rather than production workers alone, finds a six-month elasticity of 0.46 , with a long-run elasticity of $0.48 .^{32}$ Thus the Wilson and Eckstein results agree with the finding in this paper that SRIRL has vanished after six months and that reaction is complete within that time, while Nadiri and Rosen and Brechling find a long-run elasticity well below that found in this paper. All three studies agree, however, that the six-month elasticity is almost as large as, or larger than, the long-run elasticity.

29. "Short-Run Productivity Behavior in Manufacturing."

30. In an attempt to make quarterly lag distributions comparable to the monthly results of this paper, the total response through the sixth month is measured as the sum of coefficients on the contemporaneous quarter, the first lagged quarter, and two-thirds of the second lagged quarter. The numbers discussed in this paragraph were obtained by adding the Wilson-Eckstein equation (b) of Table 1 to their equation from Table 3 (adding the straight-time hours equation to the overtime hours equation) and multiplying through by $C_{t}$, the capacity output variable at time $t$. The resulting equation makes manhours a distributed lag function of output plus a capacity effect. The coefficients in the equation are themselves functions of $t$, which is zero in 1948:4 and increases by one in each quarter thereafter. I have taken the "long-run effect" of a change in output to be that occurring when all lagged values of output have reached the new level and are equal, assuming output equal to capacity at the starting point.

31. Disequilibrium Model of Demand. The numbers that follow in this paragraph were derived from the Nadiri-Rosen Table 4.1, p. 59, by the methods given in their section D1, pp. 73-75, and in particular equation (4.3), p. 73. Separate results for log of hours per man and log of employment were added to obtain implied results for total manhours.

32. "The Relationship between Output and Employment in British Manufacturing Industries," Review of Economic Studies, Vol. 32 (July 1965), p. 213, equation (Avi). 


\section{Evidence on Forecasting by Firms}

The significant lag in reaction of labor to output in all industries in the face of insignificant values for future output in most industries suggests that firm forecasts of aggregate industry output are not substantially better than forecasts from its current and past values. If firms could forecast better, and if lags in adjustment of labor are generated by costs of adjustment, then firms should be able to profit by making labor depend on future output. Also, since costs of adjustment are presumably greater for employment than for manhours, the importance of future output should be greater when employment is the dependent variable if firm prescience were the source of significant future coefficients. Neither the results for total manufacturing with sales the output variable nor those for the paper industry fit this pattern, though the apparel industry does.

Finally, if firms know future output, it would be pure chance if the resulting two-sided regression relation for labor on output had a one-sided inverse, making output a function of current and past labor only. In every case in which future output enters significantly, the regression in the other direction passes a test for one-sidedness. ${ }^{33}$

\section{Recent Productivity Behavior}

Productivity in manufacturing has been low relative to its predicted value throughout the 1973-74 period. This can be seen from Figure 1, which shows the actual and predicted values of manufacturing manhours along with the errors of the predictions-the difference between predicted and actual-from an equation similar to that presented earlier. ${ }^{34}$ The values

33. Here again, apparel is a partial exception in that the regression of output on employment, while not significantly in conflict with the hypothesis of a nonzero first future coefficient arising from time aggregation, has an implausibly large point estimate for the first future coefficient if time aggregation is the explanation.

34. The equation used to generate this section was estimated from the post-1963 part of the sample period only, since a significant change in the equation's parameters had been detected at 1963. Also, lags 13 through 24 were dropped from the lag distribution in the estimation. The frequency-domain serial-correlation correction used in the estimation technique for this paper produces residuals that do not have the usual interpretation as conditional forecast errors. In effect, the correction for serial correlation during estima- 
given in the figure are percentage deviations from trend and measure the percentage errors in an implied prediction of productivity.

Two kinds of residuals are shown in the figure. The first is simply the difference between predicted and actual manhours for each month. The second takes account of the serial-correlation correction estimated in fitting the equation and uses it in adjusting each month's prediction for the error in the previous prediction. The uncorrected residuals show the shortfall in the level of productivity (the excess in the level of manhours over the predicted level) rising from about 2 percent at the start of the period to about 4 percent at the end of the period, with variations during the intervening months. The errors are exceptionally large in December 1973 and May 1974; but residuals of this size are not unique in the period for which the equation was fit. The residuals corrected for serial correlation indicate that whatever productivity mystery existed in this period was not growing persistently. The large residual for December 1973, when actual manhours held steady while predicted manhours declined sharply, is about two standard deviations. In monthly data, such a residual should occur once every two years. Another large observation is the residual for May 1974, which is about 2.3 standard errors, but it is adjacent to a residual of minus 1.8 standard errors.

Between the summer months of 1973 and the end of the data period in May 1974, the productivity shortfall widened substantially, although the reversals in the serially correlated residuals warn against interpreting this as a new pattern in the dynamic behavior of output per manhour. Rather, it seems more natural to attribute this productivity behavior to the unusual difficulties of making short-term demand forecasts in this period. A full documentation of just how irregular this period has been would require a careful comparison with past periods of decline in output. But it does

tion uses a filter involving leads as well as lags. To get residuals corrected for serial correlation that can be interpreted as conditional forecast errors, the following procedure was used. Logarithms of both variables were regressed on linear trend and seasonal dummies over 1947-73. Residuals of the FRB index from this regression were then fed through the lag distribution estimated by methods of this paper from post-1963 data to generate predicted deviations from trend for the labor variable (manhours or employment). Residuals from the regression of labor on trend and seasonals are plotted in Figure 1 as the true values. The differences between these true values and the predicted values were taken as the raw residuals, and an autoregression was fit to these residuals over 1963-74, using lags 1 through 12, 24, and 36. The residuals from this autoregression were subtracted from the true values to generate the predicted values of labor corrected for serial correlation. 
Figure 1. Productivity, Measured by Manhours per Manufacturing Production Worker, Actual and Predicted, Monthly, January 1973-May 1974
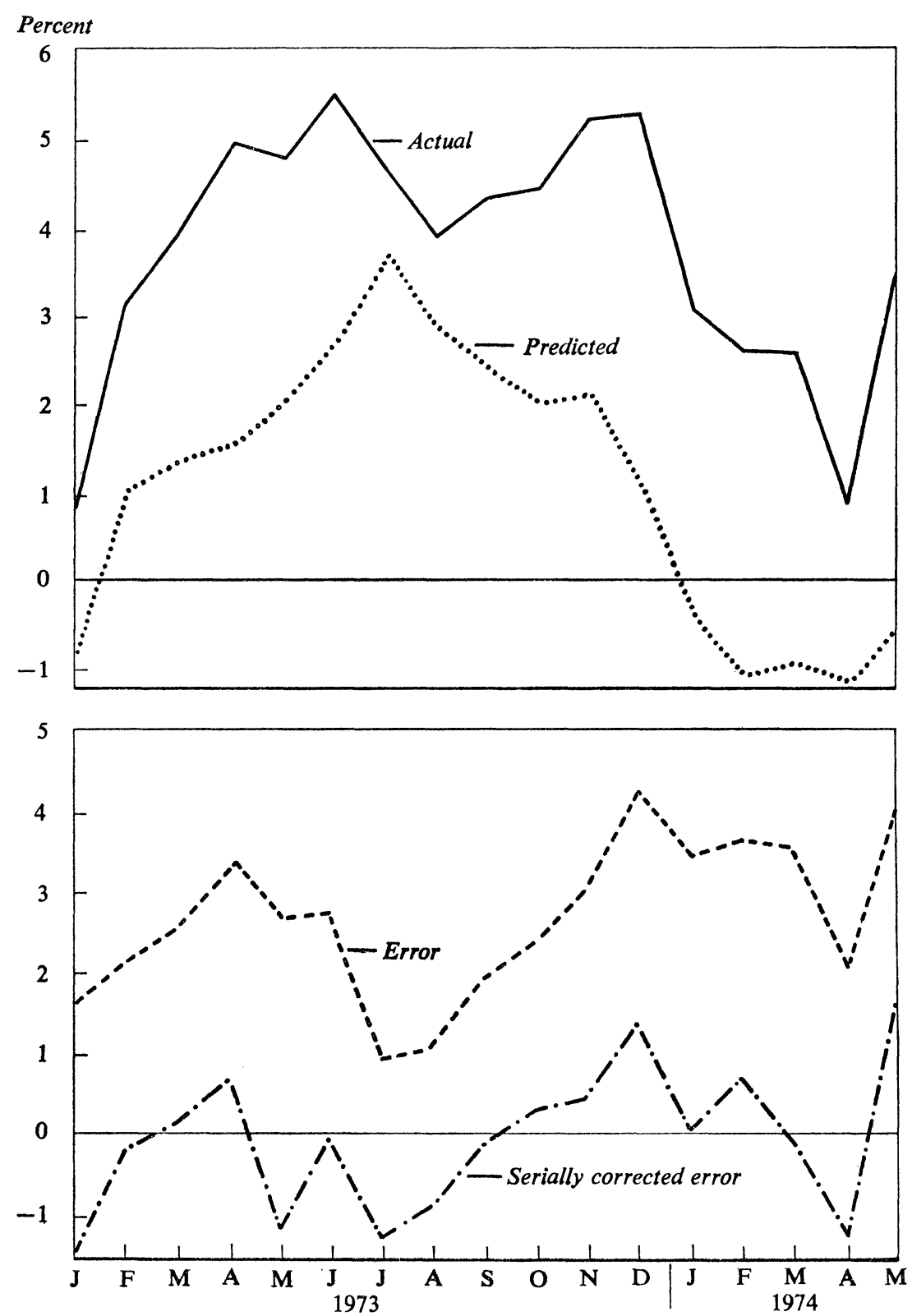

Sources: Author's simulations, using the Federal Reserve Board's index.of industrial production as the output measure. The sample period begins after 1963. 
appear that the substantial and unusual drop in productivity for the aggregate economy that has been observed between late 1973 and mid-197435 had a parallel in the productivity of production workers in manufacturing.

\section{Conclusions}

The response of labor-taken here as production workers in manufacturing-to changes in output appears to be complete within one year; the adjustment of manhours, as opposed to employment, is probably completed within six months. The response of employment appears to be less than fully proportional, even when it is complete-the phenomenon of short-run increasing returns to labor-in degrees that vary substantially across industries. There is no noticeable tendency for a high degree of SRIRL to be associated with an especially delayed completion of response. Theoretical suggestions made above showed that SRIRL that does not dwindle away in estimated "long-run responses" could arise with firms optimizing under uncertainty, even though cost and production functions have the usual convexity properties. On the other hand, in no industry except primary metals is the estimated response of manhours inconsistent with the absence of SRIRL after six months.

The results of this paper indicate that single-equation relations of output to labor in manufacturing are capable of generating results with a behavioral interpretation (as opposed to purely statistical forecasting relations), and that exogeneity tests are useful for identifying estimated regressions for which structural interpretation is hazardous.

In the three cases (all with employment as the labor variable) in which regressions of output on labor are rejected by the exogeneity tests, the estimated one-sided lag distributions all have unusual and implausible estimates of longer-run responses. Implausible estimates are not present in the regressions in the other direction, which pass the test. For manhours in total manufacturing, results with the two output measures-sales and the FRB production index-are more consistent in regressions of output on manhours, which pass the exogeneity test, than in the regressions of manhours on output, which fail it. When both directions of regression pass the

35. See Arthur M. Okun, "Unemployment and Output in 1974," Brookings Papers on Economic Activity (2:9174), Table 2, last column, p. 498. 
test, in most cases they give roughly consistent pictures of the dynamics between labor and output. ${ }^{36}$

The findings presented here do not have direct implications for rules of thumb for relating economy-wide employment to output in business cycle analysis and forecasting. Most workers are not production workers, and almost any other category of employment seems likely to adjust less rapidly, less strongly, and less consistently to movements in output. The regressions displayed should not be expected to apply to broader aggregates, and the single-equation methods used here very likely would not succeed in such applications. This paper has focused on production workers in manufacturing precisely because the labor demand functions for them are likely to be well defined and because SRIRL, if it exists, would be most paradoxical for this type of labor.

On the other hand, the results do have some implications for business cycle analysis for policymaking purposes. Labor demand regressions have universally included some sort of trending variable-for example, a polynomial in $t$, capital stock, a broken line interpolated among selected peak years of output or output per worker, "normal hours," or the labor force. The theoretical and empirical results of this paper suggest that attributing causal significance to the estimated coefficients of these trending variables is a mistake. Suppose the trend term is "capacity." Soligo estimates a distributed lag regression of employment on output whose long-run elasticity is 0.49 , and concludes that "the long-run productivity change of .51 percent is a measure of the increase in efficiency resulting from moving to a higher degree of capacity utilization." 37 This paper has shown that, within the same industry, employment demand functions are likely to have smaller long-run elasticities than manhour demand functions, and that both elasticities can be less than one in the absence of nonconvexity in the static production function. In effect, trending variables will pick up some of the explanatory power that should be associated with the anticipated path of output. An actual change in capacity utilization that did not bear the usual relation to a change in the ratio of output to its trend value would not have the effects predicted by the "capacity" coefficient in the regression.

36. In assessing this statement recall that, because of time aggregation, the very shortrun dynamics are expected not to agree across the two directions of regression.

37. Ronald Soligo, "The Short-Run Relationship between Employment and Output," Yale Economic Essays, Vol. 6 (Spring 1966), pp. 161-215 (the quotation is on p. 191). 


\section{APPENDIX}

\section{Reports of Statistical Tests}

TABLES A-1 through A-4 present the results of statistical tests for various hypotheses discussed in the text related to the regressions between output and manhours, and between output and employment, that are reported in text Tables 1, 2, 4, and 5.

Table A-1. F-Test for Null Hypothesis That Manhours-Output Manufacturing Regressions Fit Seasonally

\begin{tabular}{|c|c|c|c|c|c|c|c|}
\hline \multirow[b]{2}{*}{ Regression $^{\mathrm{a}}$} & \multicolumn{2}{|c|}{ Total manufacturing } & \multirow[b]{2}{*}{$\begin{array}{c}\text { Durable } \\
\text { goods }\end{array}$} & \multirow[b]{2}{*}{$\begin{array}{c}\text { Non- } \\
\text { durable } \\
\text { goods }\end{array}$} & \multirow[b]{2}{*}{ Paper } & \multirow[b]{2}{*}{$\begin{array}{c}\text { Primary } \\
\text { metals }\end{array}$} & \multirow[b]{2}{*}{ Appare } \\
\hline & $\begin{array}{l}\text { Index of } \\
\text { industrial } \\
\text { production }\end{array}$ & Sales $^{\mathrm{b}}$ & & & & & \\
\hline $\begin{array}{l}\text { Manhours on } \\
\text { output }\end{array}$ & 1.38 & 8.48 & 1.40 & 1.57 & 1.24 & 1.55 & 1.62 \\
\hline $\begin{array}{l}\text { Output on } \\
\text { manhours } \\
\end{array}$ & 1.70 & 1.26 & 1.79 & 1.81 & 1.36 & 1.54 & 1.49 \\
\hline
\end{tabular}

Source: The regression to be tested was estimated by the method described in note 24 above, except that the setting to zero of components of the Fourier transforms in the seasonal bands was omitted. Then, without repeating the correction for serial correlation, the Fourier-transformed data were set to zero in the seasonal bands and the final-stage OLS regression repeated. If interpreted in the frequency domain, this procedure is equivalent in large samples to omitting the frequency-domain "observations" at those harmonic frequencies that lie in the seasonal bands. Since the regressions are fit to 262 observations, the seasonal bands of the width used contain about forty-seven harmonic frequencies in addition to the eleven exact seasonal frequencies. The second regression, then, is in effect fitted to a sample with forty-seven fewer degrees of freedom, and the $F(47,176)$ statistics can be thought of as testing the significance of a hypothetical group of forty-seven dummy variables accounting exactly for the variance in those forty-seven observations.

a. $F_{0.10}(47,176) \approx 1.38 ; F_{0.05}(47,176) \approx 1.45 ; F_{0.01}(47,170) \approx 1.66$.

b. Shipments deflated by the wholesale price index for manufacturing. 
Table A-2. F-Test for Null Hypothesis That Future Coefficients Are Zero, Manhours-Output Regressions, Selected Manufacturing Industries

\begin{tabular}{|c|c|c|c|c|}
\hline \multirow[b]{3}{*}{ Industry } & \multicolumn{4}{|c|}{ Regression $^{\mathrm{a}}$} \\
\hline & \multicolumn{2}{|c|}{ Manhours on output } & \multicolumn{2}{|c|}{ Output on manhours } \\
\hline & $\begin{array}{l}11 \text { future } \\
\text { coefficients }\end{array}$ & $\begin{array}{l}12 \text { future } \\
\text { coefficients }\end{array}$ & $\begin{array}{l}11 \text { future } \\
\text { coefficients }\end{array}$ & $\begin{array}{l}12 \text { future } \\
\text { coefficients }\end{array}$ \\
\hline \multicolumn{5}{|l|}{ Total manufacturing } \\
\hline $\begin{array}{c}\text { Index of industrial } \\
\text { production }\end{array}$ & 1.001 & 0.921 & 1.308 & 2.434 \\
\hline Sales $^{\mathrm{b}}$ & 2.391 & 2.944 & 0.667 & 0.741 \\
\hline Paper & 1.404 & 1.936 & 1.012 & 1.634 \\
\hline Primary metals & 0.966 & 0.896 & 1.343 & 1.373 \\
\hline Apparel & 1.151 & 1.486 & 1.444 & 1.666 \\
\hline Durables & 0.891 & 0.957 & 0.867 & 2.041 \\
\hline Nondurables & 0.370 & 0.393 & 1.804 & 2.758 \\
\hline
\end{tabular}

Sources: Author's regressions, discussed in the text. The coefficients on lags -2 through -12 or on lags -1 through -12 (see Tables 1 and 2 ) were constrained to be zero under the null hypothesis.

a. $F_{0.05}(12,165) \approx 1.81 ; F_{0.01}(12,165) \approx 2.29 ; F_{0.05}(11,165) \approx 1.84 ; F_{0.01}(11,165) \approx 2.39$.

b. Shipments deflated by the wholesale price index for manufacturing.

\section{Table A-3. F-Test for Null Hypothesis That Lags 2 through 24 Have} Zero Coefficients in Manhours-Output Regressions Which Include Lags -1 through 24, Selected Manufacturing Industries

\begin{tabular}{|c|c|c|c|c|c|c|c|}
\hline \multirow[b]{2}{*}{ Regression $^{\mathrm{a}}$} & \multicolumn{2}{|c|}{ Total manufacturing } & \multirow[b]{2}{*}{$\begin{array}{c}\text { Durable } \\
\text { goods }\end{array}$} & \multirow[b]{2}{*}{$\begin{array}{l}\text { Non- } \\
\text { durable } \\
\text { goods }\end{array}$} & \multirow[b]{2}{*}{ Paper } & \multirow[b]{2}{*}{$\begin{array}{c}\text { Primary } \\
\text { metals }\end{array}$} & \multirow[b]{2}{*}{ Apparel } \\
\hline & $\begin{array}{c}\text { Index of } \\
\text { industrial } \\
\text { production }\end{array}$ & Sales ${ }^{\mathrm{b}}$ & & & & & \\
\hline $\begin{array}{l}\text { Manhours on } \\
\text { output }\end{array}$ & 2.90 & 2.45 & 3.12 & 2.53 & 1.67 & 1.67 & 3.27 \\
\hline $\begin{array}{l}\text { Output on } \\
\text { manhours }\end{array}$ & 2.23 & 2.40 & 2.64 & 1.64 & 2.02 & 1.68 & 1.50 \\
\hline
\end{tabular}

Sources: Author's regressions, discussed in the text. See Tables 1 and 2 for the lag distributions. a. $F_{0.05}(23,176) \approx 1.59 ; F_{0.01}(23,176) \approx 2.02$.

b. Shipments deflated by the wholesale price index for manufacturing. 
Table A-4. F-Test for Null Hypothesis That Future Coefficients Are Zero, Employment-Output Regressions, Selected Manufacturing Industries

\begin{tabular}{|c|c|c|c|c|}
\hline \multirow[b]{3}{*}{ Industry } & \multicolumn{4}{|c|}{ Regression $^{\mathrm{a}}$} \\
\hline & \multicolumn{2}{|c|}{ Employment on output } & \multicolumn{2}{|c|}{ Output on employment } \\
\hline & $\begin{array}{l}11 \text { future } \\
\text { coefficients }\end{array}$ & $\begin{array}{l}12 \text { future } \\
\text { coefficients }\end{array}$ & $\begin{array}{l}11 \text { future } \\
\text { coefficients }\end{array}$ & $\begin{array}{l}12 \text { future } \\
\text { coefficients }\end{array}$ \\
\hline \multicolumn{5}{|l|}{ Total manufacturing } \\
\hline $\begin{array}{c}\text { Index of industria } \\
\text { production }\end{array}$ & 0.68 & 0.63 & 1.57 & 2.64 \\
\hline Sales $^{\mathrm{b}}$ & 0.99 & 1.89 & 0.79 & 0.74 \\
\hline Durable goods & 0.60 & 0.56 & 1.09 & 2.35 \\
\hline Nondurable goods & 0.50 & 0.43 & 1.97 & 4.41 \\
\hline Paper & 1.14 & 1.24 & 2.40 & 2.73 \\
\hline Primary metals & 1.61 & 1.72 & 2.37 & 2.42 \\
\hline Apparel & 1.02 & 2.10 & 1.02 & 1.54 \\
\hline
\end{tabular}

Sources: Author's regressions, discussed in the text. The coefficients on lags -2 through -12 or on lags -1 through -12 (see Tables 4 and 5) were constrained to be zero under the null hypothesis.

a. $F_{0.05}(12,165) \approx 1.81 ; F_{0.01}(12,165) \approx 2.29 ; F_{0.05}(11,165) \approx 1.84 ; F_{0.01}(11,165) \approx 2.39$.

b. Shipments deflated by the wholesale price index for manufacturing. 


\section{Comments and Discussion}

Michael C. Lovell: Christopher Sims presents a fresh analysis of a much studied phenomenon: short-run increasing returns to labor, or SRIRL, which describes the tendency for fluctuations in output to be associated with less than proportionate fluctuations in labor inputs. He argues that the existing literature does not rule out the possibility that the size and duration of SRIRL that are found so regularly in the empirical work in this area are substantially biased by errors in variables. Thus his approach resembles Milton Friedman's use of the statistical errors-in-variable model in his study of the consumption function. Friedman postulated a true proportionality relationship between consumption and income and argued that the observed short-run relationship between observed consumption and income was too flat because they contain errors of observationtransient consumption and transient income. ${ }^{1}$ In the same vein, Sims argues that SRIRL may be a statistical artifact.

Sims postulates a much simpler economic model than is customary in the work of other investigators. The model proposed by Holt and his associates in 1960 invoked costs of adjustment (hiring, training, and firing costs) to explain why the work force of a cost-minimizing firm would not fluctuate as violently as output. ${ }^{2}$ And a cadre of subsequent workers used models of varying degrees of sophistication in their empirical work. Some models explicitly incorporated such variables as the capital stock, liquid assets, and inventories; some made output a decision variable determined on the basis of anticipated price and factor cost. Sims is probably correct

1. This interpretation is conveniently summarized in J. Johnston, Econometric Methods (1st ed., McGraw-Hill, 1963), note 1, pp. 148-49.

2. Charles C. Holt and others, Planning Production, Inventories, and Work Force (Prentice-Hall, 1960). 
in complaining about the lack of attention to measurement error. While I regard his treatment of employment as proportional to current and lagged output-trend corrected-a gross oversimplification, his attempt to reconcile observed fact with that simple model is intriguing.

Near the beginning of his paper Sims mentions that one of his aims is to use monthly rather than quarterly data. In principle, this practice increases the number of observations three-fold. Ray Fair, who also used monthly data, had warned of potential problems because the employment data refer to a particular sample week while the output and shipments data are, for the most part, based on the whole month. ${ }^{3}$ With a clever example presented in his first two text tables, Sims demonstrates that these temporal shift and aggregation effects may introduce a psuedo-distributed lag relationship and artificial SRIRL when in fact labor is proportional to current output.

Seasonality is another controversial problem. Fair had criticized the use of seasonally adjusted data in earlier studies, arguing that the seasonal movement in sales should be captured by seasonal movement in output. In contrast, Sims feels that the monthly data should be seasonally adjusted, and he utilizes a sophisticated procedure to do so. One cost is a loss of observations: his technique curtails his sample period from the basic 1947-73 span to March 1950 through December 1971. He does reveal in Table A-1 that dummy-variable seasonal adjustment flunks the $F$-test in nine of fourteen cases. My guess is that a somewhat more elaborate set of dummy variables, allowing for a moving seasonal, might have done the trick. But a more sophisticated approach would be to rely on the economic arguments advanced by Modigliani and his co-authors long ago. First of all, Modigliani and Sauerlender argued that firms confronted with markedly seasonal sales are likely to have a planning horizon of a year; ${ }^{4}$ hence Sims might have truncated his lead and lag distributions at twelve rather than twenty-four months. Second, Modigliani and Sauerlender argued-in a departure from Fair-that the coefficients in the production scheduling model are themselves subject to seasonal variation-that is, the response to anticipated sales and to previous errors will depend upon how close the

3. Ray C. Fair, The Short-Run Demand for Workers and Hours (Amsterdam: NorthHolland, 1969).

4. Franco Modigliani and Owen H. Sauerlender, "Economic Expectations and Plans of Firms in Relation to Short-Term Forecasting" in Short-Term Economic Forecasting, Conference on Research in Income and Wealth (Princeton University Press for the National Bureau of Economic Research, 1955). 
firm is to the seasonal peak or trough in sales. This notion suggests that separate regressions for each season might be useful, possibly with some sort of a dummy to fudge for variations in the number of working days in each month, followed by the customary $F$-test to determine whether, in fact, pooling over seasons is appropriate.

Sims discusses other types of measurement error. For example, he points out that the sample used in estimating sales is much smaller than that for employment data. And a problem may arise because employment data were used in the construction of the FRB industrial production index. One might presume that the presence of substantial measurement error in both variables would mean that the standard regression model is not appropriate; Sims runs things both ways, but in a majority of industries his exogeneity test rejects neither direction of regression. He suggests that either direction will uncover the true dynamics; presumedly, errors of measurement in both variables mean that either direction will involve bias, although not necessarily of sizable magnitude.

I think that Sims is to be congratulated for skillfully executing a wellconceived project on an intriguing question. It certainly is useful to know that the manhour input generally adjusts in proportion to output changes within six months. My major reservation concerns the appropriate mix between econometric versus economic sophistication. Sims works with an exceedingly simple model and does not find it helpful to distinguish between shipments and output. In contrast to Solow and Soligo, ${ }^{5}$ he does not incorporate the capital stock in the regressions, hoping that this variable can be netted out by trend. While Sims debates with himself about whether output or labor is exogenous, Schramm worked with a model in which both variables are endogenous. ${ }^{6}$ I prefer the more elaborate models because of their richer economic content, for the same reason that I prefer the lifecycle to the permanent-income hypothesis. Sims' extremely simple model carries him far once errors of observation and aggregation are given their due. And, in the current state of the economy, it is indeed interesting to

5. Robert M. Solow, "Technical Progress, Capital Formation, and Economic Growth," in American Economic Association, Papers and Proceedings of the Seventyfourth Annual Meeting, 1961 (American Economic Review, Vol. 52, May 1962), pp. 76-86; Ronald Soligo, "The Short-Run Relationship between Employment and Output," Yale Economic Essays, Vol. 6 (Spring 1966), pp. 161-215.

6. R. Schramm, "The Influence of Relative Prices, Production Conditions and Adjustment Costs on Investment Behaviour," Review of Economic Studies, Vol. 37 (July 1970), pp. 361-76. 
learn that while no substantial long-run productivity changes will be associated with changes in output, the short-run cushioning effect of SRIRL will not persist long in a period of anticipated stagnation.

Robert M. Solow: The most important results of this paper are summarized in Table 3. That table shows an almost proportional cumulative response of manhours of production workers to output, with the strongest response in the contemporaneous month and the full response completed within six to nine months. There is evidence for this finding in all industries reported except paper and possibly primary metals. Such results are of interest for two main reasons: they can guide the interpretation of monthly unemployment statistics and they can help in analyzing the short-term employmentoutput relation in macro models.

If the manhours for all workers were like those of production workers in manufacturing, then Sims' results would support a statement that the adjustment of manhours to output takes only about two quarters-indeed, that the response of employment to output is about 80 percent complete in this time. As Sims points out, however, only a small fraction of all workers are manufacturing production workers; so more insight into the rest of employment is required before results like his can be used to interpret economy-wide developments. But his projections for 1973 and early 1974 do coincide with the economy-wide finding reported by Okun (BPEA, $2: 1974)$ that the response of unemployment to output was unusually delayed in this period.

On the analytic issue, a lot of the paradox of short-run increasing returns to labor in macro models has evaporated in this paper. First, Sims estimates nearly constant returns to labor. The differences between his estimates and unity are mostly statistically insignificant. Even if a purist would prefer diminishing returns to labor, it hardly matters.

Second, there are overhead workers, even among those who are classified in the data as production workers in manufacturing. Their existence is not explicitly allowed for in the estimation process, so it makes the finding of constant, or even increasing, returns to labor not surprising at all.

A third reason why a finding of constant returns to labor in the short run does not disturb me is that short-run variations in other inputs, especially the services of plant and equipment, are not directly observed, so they cannot be held fixed. If, for instance, the proper model is fixed proportions between the services of plant and equipment and of production workers in the short run, then the movement observed is really one along an expansion 
path, and not in one variable alone. The cumulative elasticity is to be interpreted as short-run returns to scale rather than to labor alone. In that case unity would be a very cozy value, not at all hard to accept.

Finally, Sims makes an important analytic point in discussing rational expectations that I think can be made more general. Suppose, for instance, that labor requirements are proportional to output statistically so that proportionality is really the rule. If employers know that sales will be a random variable, fluctuating around a constant mean value, and if it is much cheaper to produce a constant mean value of output and meet fluctuations in sales from inventories rather than by variations in production, then labor employment and manhours will be constant. A regression of employment on sales will show a zero sum of coefficients. This is fundamentally measurement error. If one could measure output correctly, one would find labor proportional to output. I think that Sims underestimated the importance of this result by tying it too closely to rational expectations. Much the same thing would follow if employers thought incorrectly that sales would fluctuate as a serially uncorrelated disturbance around a constant mean value. All one needs is that kind of belief about the behavior of output.

I have questions about a couple of points concerning the results. In most of the industries, especially in apparel and paper, the regression of output on manhours appears inconsistent with the regression of manhours on output. In exact terms, if the cumulative response in one case is less than one, the response in the other case ought to be greater than one. If that relation between the two directions is not necessarily true in statistical terms, the reason ought to be explained. Furthermore, I would like to have the trend terms from these regressions to see whether they are plausible in sign and in magnitude. How one interprets the results depends upon the plausibility of these trend terms.

It is cheap to invent difficult things for people to do. However, I suspect there is an asymmetrical cyclical response of manhours to output. It would be useful if Sims could allow for different responses depending upon whether output is rising or falling.

\section{General Discussion}

Franco Modigliani related Sims' results to his own view that most productive factors are approximately fixed in the short run, suggesting con- 
stant returns to labor as a first approximation. The existence of some overhead labor-or of labor used for a time on overhead jobs, such as painting walls-tilts the balance toward increasing returns; while the mixture of vintages in the capital stock with which labor works tilts it toward decreasing returns. Which effect dominates at a particular time is hard to predict, at least until very high levels of utilization are reached; but Modigliani was not surprised at Sims' finding of approximately constant returns on balance.

Other panel members discussed aspects of the production and employment decision that might affect cyclical productivity. Arthur Okun asked why fluctuations in inventories rather than labor input should not be expected to accommodate most of the short-run variation in demand. A model that allowed for this effect might produce different elasticity estimates. Daniel Brill noted, however, that holding inventories lays substantial carrying costs on the firm. R. A. Gordon shared Robert Solow's concern that the ups and downs in economic activity should be separated. He noted that the costs of hiring and laying off workers would affect productivity as much as the presence of overhead labor would, and these turnover costs would be asymmetric between rising and falling periods of the business cycle.

The inadequacies of the FRB production indexes as measures of output drew some comment. Okun and Robert J. Gordon noted the inaccuracies associated with including in production only finished goods and not goodsin-process. For example, a truck engine would not be counted in the FRB index if it were produced by General Motors, but would be if it were produced by an engine company. Others pointed to the use of electricity input to measure output for some industries as well as the use of labor input that Sims had discussed. Lawrence Klein argued that, at the industry level, gross output would be a better index than value added since it could be measured more accurately and avoided the necessarily uncertain estimates of inputs.

Klein and Charles Holt seconded Michael Lovell's interest in a fuller model to support the empirical work. Sims replied that the single equation he estimated could have been derived from a complete model with many inputs, and cited the work of Nadiri and Rosen which did precisely that. Klein remained unpersuaded that the estimations could be interpreted as anything more than correlations between the labor and output variables. They appeared to be neither structural production function relations- 
which would require technical information about production lags-nor structural labor demand functions-which would require other variables, such as relative prices. Sims responded that production function and labor demand relations need not be different, although the hiring response to current and future output that he modelled did explicitly make his equation one describing labor demand. The exogeneity test indicated that the equations were capturing the dynamics between labor and output, although they did not offer a particular structural interpretation of the relation. Sims did not put relative factor prices in his model because they change slowly and, on evidence of work by others, enter the estimates with the wrong sign. Holt and Saul Hymans objected that, while including relative factor prices in the equation posed problems, omitting them, or any other relevant variable such as labor market conditions, cast doubt on the estimates of the sum of the coefficients on output.

R. J. Gordon described his own labor demand equation, which is similar to Sims' except that it relates total private nonfarm manhours to private output. The sum of the coefficients on output is between 0.65 and 0.85 , somewhat lower than Sims' estimates presumably because of the presence of more overhead labor. This equation, which has sufficient coverage to say something meaningful about global productivity, was 2.3 percent below its forecast level for the third quarter of 1974. A slightly larger shortfall was experienced in 1969, and a smaller, although still distinct, shortfall in 1956. These were all periods of stagnant or declining output. But similar errors are not observed for other periods of decline. 